(c) American Dairy Science Association, 2006.

\title{
Effect of Rubber Flooring on Claw Health in Lactating Dairy Cows Housed in Free-Stall Barns
}

\author{
J. Vanegas, ${ }^{1}$ M. Overton,† S. L. Berry, $\ddagger$ and W. M. Sischo* $\S$ \\ *University of California Davis, Veterinary Medicine Teaching and Research Center, Tulare 93274 \\ †University of Georgia, College of Veterinary Medicine, Department of Population Health, Athens 30602 \\ fUniversity of California Davis, Department of Animal Science, Davis 95616 \\ §University of California Davis, Department of Population Health and Reproduction, Davis 95616
}

\begin{abstract}
Multiparous dairy cows between 10 to $30 \mathrm{~d}$ in milk (DIM) were enrolled in a clinical trial to evaluate the effects of rubber flooring on the development of claw lesions, locomotion scores, clinical lameness, and rates of hoof growth and wear. Two groups of cows were housed in identical free-stall facilities, except that 1 pen (rubber, $\mathrm{n}=84$ ) had rubber alley mats covering the entire concrete floor of the pen, whereas cows in the second pen were exposed to concrete flooring (concrete, $\mathrm{n}=82$ ) without rubber alley mats. All cows were evaluated 3 times between 10 and 30,74 and 94, and 110 and 130 DIM for 1) the presence of claw lesions on their rear feet, 2) the occurrence of clinical lameness based on a locomotion score, and 3) rates of claw growth and wear as observed on the dorsal wall of the right lateral claw. No differences between flooring groups at the time of enrollment were detected for lactation number, mean DIM at first examination, body condition score, and proportion of cows with claw lesions at the first examination. Odds of developing claw lesions between examinations were not different for cows exposed to the rubber surface compared with those exposed to concrete. Cows on concrete, however, had greater odds of developing or exacerbating existing heel erosion than cows on rubber flooring. Regardless of the flooring surface, the lateral claw was more likely to develop lesions than the medial claw. Odds of becoming lame by the third examination and the proportion of cows requiring therapeutic hoof trimming because of lameness were greater for concrete-exposed cows than those on rubber. Cows on rubber flooring had decreased claw growth and wear between the first and last examination compared with cows on concrete. Regardless of flooring surface, second-lactation cows had greater wear rates than those in third or greater parities. Results of our study
\end{abstract}

Received December 15, 2005.

Accepted April 28, 2006.

${ }^{1}$ Corresponding author: pajvanegas@comcast.net suggest that a soft flooring surface, such as interlocking rubber, is beneficial for hoof health.

Key words: rubber flooring, claw health, lameness, dairy cows

\section{INTRODUCTION}

Lameness is one of the most important diseases of dairy cattle because of its negative impact on milk production (Coulon et al., 1996; Warnick et al., 2001), reproductive efficiency (Lucey et al., 1986; Collick et al., 1989), and health and animal well-being. Lameness is common among dairy cows and estimates of its incidence ranged from 13 to $53 \%$ depending on the diagnostic criteria used to classify it and the type of confinement system in which cows are managed (Wells et al., 1993; Clarkson et al., 1996).

Multifactorial etiologies have been incriminated in the development of lameness. Some studies have identified diets containing elevated concentrations of fermentable carbohydrates as a major risk factor for lameness (Livesey and Fleming, 1984; Peterse et al., 1984). However, there are also physiological (Offer et al., 2000; Lischer et al., 2002), behavioral (Colam-Ainsworth et al., 1989), anatomical (Toussaint Raven, 1985; Ossent and Lischer, 1998), and environmental factors (Bergsten, 2001) that significantly affect development of the condition.

Housing systems have repeatedly been associated with lameness in dairy cows. Currently, free-stall housing is one of the primary confinement systems used for dairy cows. Free-stall barns (as well as other systems, including tie-stall barns) are often built on durable and easy-to-clean materials such as concrete. Although concrete has distinct advantages as a building material, it can be harsh and abrasive to the cow's hooves. Several studies have reported increased incidence of claw lesions and clinical lameness or differences in growth and wear indices in cows exposed to concrete flooring compared with cows housed on flooring surfaces such as dirt (Vermunt and Greenough, 1996), straw yards (Somers et al., 2003), or rubber slats in tie stalls (Hult- 
gren and Bergsten, 2001). Others also have found that inadequate free-stall design and lack of bedding material increases incidence of lameness (Faull et al., 1996).

Many free-stall dairy operations currently have partial rubber flooring in their free-stall barns. Rubber floors are often installed in selective areas in which cows spend a significant amount of time standing or walking (i.e., feeding alleys and return walking lanes) with the perception that a softer surface will reduce pressure on the claws, reduce incidence of lameness, and lessen claw growth and wear. Despite the increased interest in and use of rubber flooring, however, few reports describe its effectiveness in preventing claw lesions and decreasing lameness. Recent studies using this type of flooring material have found improvements in claw health (Jungbluth et al., 2003) and the locomotion behavior of cows having different degrees of lameness (Telezhenko and Bergsten, 2005). Vokey et al. (2001) tested different feeding alley (concrete and rubber) and free-stall (concrete; mattress and sand) surfaces with a group of lactating dairy cows housed in a conventional free-stall barn. Although the combination of interlocking rubber alley surfaces with sand stalls was related to increased claw growth, the authors concluded that rubber alley surfaces did not prevent claw lesions. However, this study (Vokey et al., 2001) was possibly confounded by group differences in the average DIM and lactation number. This is of particular importance because previous studies have shown that incidence of lameness is greater during the first weeks after calving, and that a relationship exists between lameness and lactation number (Greenough and Vermunt, 1991; Offer et al., 2000). At this point, the evidence supporting the use of rubber mat flooring is not strong and does not directly address the effect of rubber flooring on claw health of the mature, early-lactation cow.

The objective of this study was to determine the effect of rubber alley mats on hoof health in multiparous cows. The specific outcomes we measured were the occurrence of claw lesions and clinical lameness, and hoof growth and wear in dairy cows exposed to rubber flooring compared with cows housed on concrete floors.

\section{MATERIALS AND METHODS}

\section{Herd and Cow Characteristics}

Cows enrolled in the study were part of a 950-cow, commercial Holstein free-stall dairy farm located in the central valley of California. Herd average 305-d milk production was approximately $11,000 \mathrm{~kg}$ per cow. Lactating cows were housed in free-stall barns and milked twice daily. Dry, prepartum, and postparturient cows were maintained in an open dirt exercise pen with shade structures. As part of the regular management of the dairy, the claws of all cows were trimmed at dry off by a professional hoof trimmer. After calving, all cows, regardless of lactation number, were moved to a fresh pen in which they were milked four times daily and their health was monitored for approximately 15 to $25 \mathrm{~d}$. Subsequently, primiparous and multiparous cows were separated and moved to early-lactation pens, where they were housed for approximately $150 \mathrm{~d}$. Cows in the dry and early-lactation pens were fed a TMR twice daily that met or exceeded NRC requirements for prepartum and early-lactation animals. Fresh cows were fed a similar TMR ration 3 times daily (NRC, 2001).

\section{Experimental Cows}

Cows were enrolled between October 2004 and February 2005. All multiparous cows between 10 and 30 DIM were eligible to be included in the study. Cows were excluded from the study when they presented a lameness score of 4 (lame) or 5 (severely lame). This score was determined using a 5-point locomotion scoring system based on posture and gait (Sprecher et al., 1997). Cows also were excluded if they presented a condition that required intervention therapy by the hoof trimmer (i.e., application of wood blocks or significant removal of claw horn to treat a hoof disease).

\section{Housing Facilities for Study Cows}

The study cows were housed in a California-style, 4row free-stall barn, with a roof slope of 4/12. The barn was oriented east to west with 2 identical free-stall pens separated by $8 \mathrm{~m}$ of feed alley. The basic flooring in both pens had identical concrete grooves, using an approximate $10-\mathrm{cm}$ square pattern. Each pen had 580 $\mathrm{m}^{2}$ of walking surface including 3 crossover areas (one in the center and one at each end of the pen), 96 selflocking stanchions, 100 free stalls, and 3 water troughs located in the same relative location in each of the pens at the crossover areas. Free stalls in both pens were bedded and groomed twice weekly with dried cow manure on the same day during the morning milking. A water flushing system was run twice daily at approximately the same time to remove manure from the pens. Farm and study personnel were diligent in maintaining 100 to 105 cows in each pen during the study. Study personnel evaluated the management and care of freestall beds to ensure that pens were managed identically. Because pens were in the same barn, the solar exposure was similar in both pens. Similar numbers of ventilation fans were mounted above the self-locking stanchions in each pen and activated using the same ther- 
mostat. It should be noted that the fans were used only during the last 2 mo of the study.

A single TMR balanced for mature, early-lactation cows was prepared and fed identically to cows in both pens. The TMR was delivered twice daily at approximately $0600 \mathrm{~h}$ and again at $1300 \mathrm{~h}$. Feed was delivered to both pens one after the other with no interruption.

There were no differences in the time cows were locked in feedline stanchions between pens. Cows in both pens were locked once daily between 6:00 and 7:30 a.m. for reading of tail chalk and AI. Twice weekly, cows in both pens were locked for an additional hour to collect data for the study. All cows were locked and released from the feedline lockups at same time.

Study cows were milked twice daily. Because cows were housed in the same barn, the distance to the milking center was identical for each pen. The milking process was identical for each cow and included udder washing in a wash pen and drying in a drip pen. Cows were moved to the milking center approximately 20 to 30 min before their scheduled milking time to allow enough time for udder preparation. Total time for a pen of cows to be moved and returned to the pen was approximately $1.5 \mathrm{~h}$ and was identical for both pens. The pens within the barn were milked consecutively.

For the study, the south-side pen was randomly selected to have the rubber alley mats (Animat, SaintÉlie d'Orford, Quebec City, Canada) installed to cover the entire concrete floor of the pen (rubber), whereas flooring on the north-side pen was left unchanged (concrete).

\section{Experimental Design}

On a weekly basis, dairy cows between 10 and 30 DIM were allocated randomly to each of the 2 study groups (rubber vs. concrete) by using a computer-based random number generator (Microsoft Excel, Microsoft Corporation, Redmond, WA) in a fixed randomization method (Meinert and Tonascia, 1986). No additional stratification was attempted in the allocation process. At the time of enrollment, rear claws of all cows were trimmed based on the Dutch 5-step method (Shearer and van Amstel, 2001) and evaluated for the presence of rear claw lesions. In addition, each cow was assigned a clinical lameness score using a 5-point scoring system (Sprecher et al., 1997) and a BCS using a 5-point BCS scale (Ferguson et al., 1994). To measure growth and wear during the course of the study, the lateral claw of the right rear foot was marked on the dorsal wall with a soldering iron $3 \mathrm{~cm}$ below the periople. Growth was measured as the change in distance from the distal periople to the mark and wear as the change in distance from the mark to the tip of the toe. During the study,

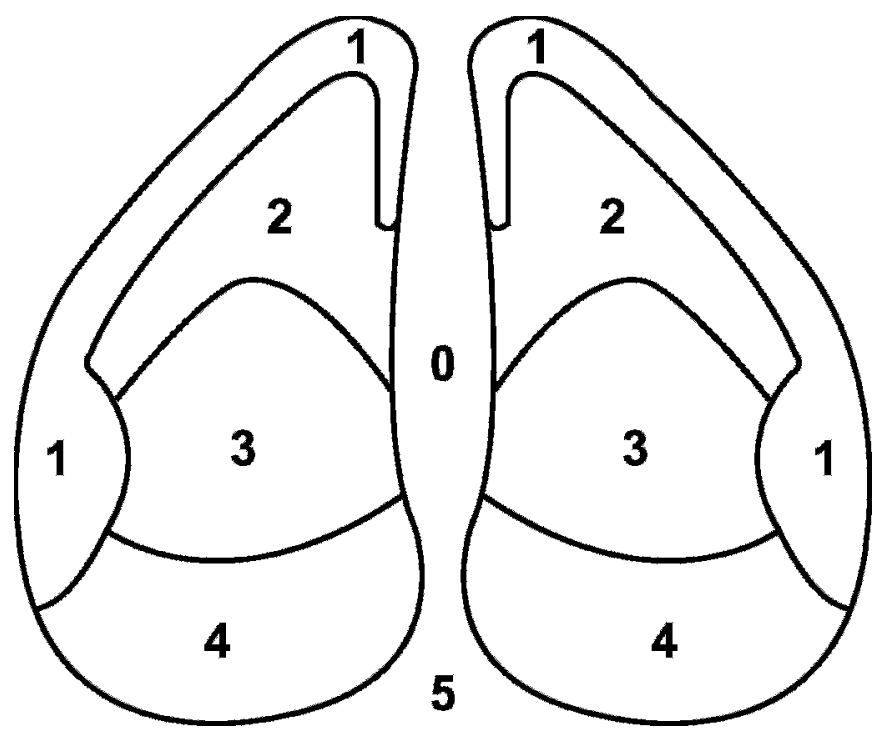

Figure 1. Diagrammatic representation of the bovine foot and zones used in evaluating hoof lesions, adapted from a study evaluating the impact of rubber flooring on hoof health (adapted from Shearer et al., 2004). Reprinted by permission of the American Association of Bovine Practitioners.

cows were evaluated at enrollment, and twice during the study follow-up, between 74 and 94, and 110 and 130 DIM.

\section{Assessment of Claw Health}

For claw health evaluations, the palmar surface of the claw was divided into 6 zones (Figure 1). Approximately $1 \mathrm{~mm}$ of solar horn was pared to create a clean surface to visualize lesions. Claw lesions were classified as sole hemorrhages (blood-stained areas on the horn of the sole), digital dermatitis (superficial dermatitis located on the plantar aspect of the foot between the bulbs of the heels), interdigital dermatitis (superficial dermatitis located in the interdigital space), heel erosion (erosion of the bulbs), interdigital phlegmon (foot rot: necrotizing infection of the skin and underlying soft tissues in the interdigital space), interdigital fibroma (korn, hyperplasia of the interdigital skin), sole ulcers (a full thickness defect in the sole with dermis visible), vertical wall cracks (vertical cracks anywhere on the wall), sole separation (widening of the white line area), and sole or white line abscesses (septic localized infection on the horn of the sole or white line with accumulation of purulent fluid).

Because the person evaluating the lesions in the field was not blinded to treatment allocation during the different observation periods, we evaluated the independence of claw scoring by taking digital photographs of every cow's rear claws for future rescoring. At the end of 
the study, the on-farm evaluator, blinded to treatment allocation, scored claws based on the digital images. The same scoring system used in the field evaluations was used for the blinded evaluation.

\section{Locomotion Scoring}

At each of the observation periods, the locomotion score of each cow was determined. This score was determined using a 5 -point locomotion scoring system based on posture and gait (Sprecher et al., 1997). Cows were evaluated in their assigned pens during the morning lockup. Two people participated in the evaluation. One person was assigned to free the cow to be evaluated from the headlock while the other person, inside the pen, evaluated the cow from the side and rear when she moved away from the lockups. Every cow was evaluated in her assigned pen by the same person each time.

Before the start of the study, the principal investigator trained the herdsman, assistant herdsman, and hoof trimmer on locomotion scoring and (for the hoof trimmer) identification of the different claw lesions. During the study, any cow observed to be lame (locomotion score 24 ) by farm personnel was separated and presented to the professional hoof trimmer for further evaluation and treatment. Lameness was detected by farm personnel in the parlor during milking or in the free stalls while cows were inseminated or being pushed to the milking parlor, or both. This information was used to assess incidence of clinical lameness observed by the farm workers.

\section{Statistical Analyses}

For analysis purposes, intervals between examinations were denoted as: INT1 = period between enrollment and the second examination; INT2 = period between the second and third examinations; and INT3 = period between the first and third examinations. Because of herd management decisions, intervals between observations were not evenly spaced, with the time between enrollment and the second exam being $64 \mathrm{~d}$, and the interval between the second and third exam being $36 \mathrm{~d}$. Statistical models for each outcome were repeated for each of the intervals.

Severity of claw lesions was determined at every examination and calculated as the number of lesions occurring in all the zones of both rear feet of each cow. Based on 4 areas of the claw and 2 areas on their surrounding hoof tissue, along with 10 different claw lesions (6 occurring on the claw and 4 on the soft tissues), the maximum severity score for both rear claws was 34 .

Severity values from the first examination were subtracted from the severity values at the second and third evaluations, and the final calculation was categorized into 3 levels: 1) "better," when severity of the lesions decreased by the second or third examination; 2) "same," when severity of the claw lesions was the same between exams; and 3) "worse," when severity of the lesions increased on subsequent examinations. Logistic regression was used to determine the between-examination odds ratio for being in an ordinal category of "better," "same," or "worse." Because the effect of rubber mats may be differential on lesion type, all analyses were also conducted stratified by lesion.

Pearson's correlations ( $r$ ) were determined between claw scores observed on the farm and claw scores observed in the digital pictures conditional on experimental group.

Based on the locomotion scores at each observation period, cows were categorized into 2 groups: "not lame" when the cow had a locomotion score of 1 or 2 , and "lame" when the locomotion score was $\geq 3$. For each cow, an outcome variable was created based on the difference in locomotion scores at the beginning and end of the study interval. Cows beginning the evaluation period as "lame" were categorized as "improved" or "still lame." Cows categorized as "not lame" at the beginning of the interval were categorized as "became lame" or "still not lame." For each category of cows (lame or not lame), a logistic model was used to calculate the betweenexamination odds ratio for "became lame" relative to "still not lame" and "improved" relative to "still lame," conditional on the type of floor surface. Growth and wear rates between examinations conditional on the type of floor surface were analyzed using a GLM.

In all statistical analyses, floor surface (rubber or concrete) was the main effect evaluated and was forced into all models. Lactation number (second, third, or fourth and greater), DIM at the time of each evaluation, and interaction between pen and lactation number were evaluated as potential confounders. A stepwise selection method was used to include or exclude the terms into the model. Contribution of the different variables was tested for significance using a partial $F$-test or Wald statistic. Based on these statistics, the final models retained only variables that were significant $(P \leq 0.05$, with the exception of the treatment main effects).

\section{RESULTS}

A total of 204 lactating dairy cows were initially enrolled in the study, with 166 cows completing the 3 examinations (rubber $=84$ and concrete $=82$ ). Thirtyeight cows (19\%) did not complete the study (rubber = 18 and concrete $=20$ ). Reasons for not completing the study were: 1) early movement from the study pens to a bull breeding pen $($ rubber $=7$; concrete $=11$ ) and 2 ) 
sale or death $($ rubber $=11 ;$ concrete $=9$ ). No significant differences between flooring types for cows at enrollment were observed for lactation number, BCS, and mean DIM at first examination. Using the cow as the unit of analysis, we found $13(15.5 \%)$ and 14 (17.1\%) of the rubber- and concrete-exposed cows, respectively, to have no claw lesions during the first examination. For those having lesions, sole hemorrhages were present on 63 and $62 \%$, heel erosion on 56 and $60 \%$, white line separation on 12 and $7 \%$, digital dermatitis on 1 and $6 \%$, and vertical fissures on 2 and $4 \%$ of the cows assigned to rubber or concrete flooring, respectively.

\section{Claw Lesion Scores}

Good agreement $\left(\mathrm{r}_{\mathrm{s}}=0.88\right)$ occurred between claw lesions scored in the field and claw lesions scored by the use of digital photographs. More important, no differences in the agreement between study groups $\left(\mathrm{r}_{\text {concrete }}=0.88, \mathrm{r}_{\text {rubber }}=0.88\right)$ were detected, indicating no observer bias in the field evaluations. Because we felt the quality of the field evaluations was greater than those from the digital pictures, we used the field data for all analyses.

Overall, the odds of claw lesions at INT1, INT2, or INT3 of "not improving" or "becoming worse" did not differ for cows exposed to the rubber surface compared with those exposed to the concrete surface $\left[\mathrm{OR}_{\mathrm{INT} 1}=\right.$ $1.15,95 \% \mathrm{CI}=0.75$ to $1.78 ; \mathrm{OR}_{\mathrm{INT} 2}=0.93,95 \% \mathrm{CI}=$ 0.63 to $1.36 ; \mathrm{OR}_{\mathrm{INT} 3}=1.01,95 \% \mathrm{CI}=0.66$ to 1.57 (where $\mathrm{OR}=$ odds ratio and $\mathrm{CI}=$ confidence interval)]. This response was not affected by lactation number, claw, or severity of the lesion at first examination or DIM at the time of the examination. When data were analyzed by lesion type for heel erosions, however, cows on concrete were more likely to have "no improvement" or "worsen" on follow-up exams than cows on rubber. This effect was observed at INT1 and INT3, for which the odds ratios were $3.9(95 \% \mathrm{CI}=1.53$ to 10.2$)$ and 3.6 $(95 \% \mathrm{CI}=1.45$ to 9.14$)$, respectively. No differences were observed for other lesions such as hemorrhage, sole ulcer, or digital dermatitis.

Regardless of the flooring surface, the lateral claw was more likely to have more severe claw lesion scores than the medial claw. This was true for all 3 intervals of evaluation $\left(\mathrm{OR}_{\mathrm{INT} 1}=2.1,95 \% \mathrm{CI}=1.28\right.$ to 3.41 ; $\mathrm{OR}_{\mathrm{INT} 2}=3.02,95 \% \mathrm{CI}=1.98$ to $4.68 ; \mathrm{OR}_{\mathrm{INT} 3}=4.78$, $95 \% \mathrm{CI}=2.4$ to 9.55 ), respectively.

\section{Clinical Lameness}

Study cows that were determined to be lame (locomotion score $\geq 4$ ) by on-farm personnel were treated by the hoof trimmer. Because some of these cows were treated but were removed from the study before they completed their 3 examinations, the total number of cows enrolled in each group was used for this analysis. More $(\mathrm{OR}=$ $1.73,95 \% \mathrm{CI}=0.98$ to 3.08 ) cows were treated for lameness in the concrete group (26 out of 102) than in the rubber group (15 out of 102).

\section{Locomotion Scores}

At enrollment, $62(37.3 \%)$ of the cows were categorized as "lame" (locomotion score of 3): 30 cows (36\%) in the rubber-exposed pen and 32 cows (39\%) in the concrete-exposed pen. For those categorized as "not lame" at the start of an examination interval, cows on concrete flooring were approximately $5(95 \% \mathrm{CI}=1.8$ to 13.7) times more likely to be diagnosed as lame at INT3 than cows on rubber flooring. No differences were observed at any of the other examination intervals (OR$\mathrm{INT} 1=2.5,95 \% \mathrm{CI}=0.97$ to $6.37 ; \mathrm{OR}_{\mathrm{INT} 2}=1.79,95 \%$ $\mathrm{CI}=0.57$ to 5.65 ).

For cows categorized as "lame" at the start of an examination interval, cows on the rubber flooring were as likely to remain lame as cows on the concrete floor $\left(\mathrm{OR}_{\mathrm{INT} 1}=4.21,95 \% \mathrm{CI}=0.90\right.$ to $19.73 ; \mathrm{OR}_{\mathrm{INT} 2}=1.77$, $95 \% \mathrm{CI}=0.51$ to $6.21 ; \mathrm{OR}_{\mathrm{INT} 3}=1.32,95 \% \mathrm{CI}=0.31$ to 5.64). Regardless of the flooring surface, however, second-lactation cows were $13.5(95 \% \mathrm{CI}=2.02$ to 91.28$)$ and $10.6(95 \% \mathrm{CI}=2.18$ to 51.70$)$ times more likely to improve their locomotion scores compared with fourth and greater lactation cows at INT1 and INT3, respectively. A similar response was not observed during the shorter INT2 interval $(\mathrm{OR}=4.1,95 \% \mathrm{CI}=0.90$ to 17.35$)$.

\section{Growth and Wear}

Cows on the rubber flooring had less $(P<0.05)$ claw wear during INT3 than did the concrete flooring group (Table 1). The same trends were observed for INT1 and INT2, but they were not significant. Regardless of the flooring surface during INT1 and INT3, an effect of lactation on claw wearing rates was detected in which second-lactation cows had more $(P<0.05)$ wear than fourth and greater lactation cows (Table 1).

A significant effect of the flooring surfaces on the growth rates was detected between the different examinations (Table 2). During INT2 and INT3, cows on the rubber flooring had less $(P<0.05)$ claw growth compared with the cows exposed to concrete floors. Contrary to wearing rates, no effect of lactation number on claw growth rates was detected.

\section{DISCUSSION}

\section{Claw Lesions}

No overall difference was detected in the probability of having more claw lesions for cows housed on rubber 
Table 1. Mean wear rates $(\mathrm{mm} / \mathrm{mo})$ for mature lactating dairy cows housed in free-stall barns under 2 different flooring conditions (rubber or concrete) during early lactation

\begin{tabular}{|c|c|c|c|c|c|c|}
\hline \multirow[b]{3}{*}{ Item } & \multicolumn{6}{|c|}{ Examination period $^{1}$} \\
\hline & \multicolumn{2}{|c|}{ INT1 } & \multicolumn{2}{|c|}{ INT2 } & \multicolumn{2}{|c|}{ INT3 } \\
\hline & Mean & $\mathrm{SE}$ & Mean & $\mathrm{SE}$ & Mean & $\mathrm{SE}$ \\
\hline \multicolumn{7}{|l|}{ Flooring } \\
\hline Rubber & $2.26^{\mathrm{a}}$ & 0.14 & $3.87^{\mathrm{a}}$ & 0.25 & $2.80^{\mathrm{a}}$ & 0.11 \\
\hline Concrete & $2.58^{\mathrm{a}}$ & 0.13 & $4.40^{\mathrm{a}}$ & 0.24 & $3.21^{\mathrm{b}}$ & 0.11 \\
\hline \multicolumn{7}{|l|}{ Lactation } \\
\hline 2 & $2.84^{\mathrm{a}}$ & 0.13 & $4.43^{\mathrm{a}}$ & 0.24 & $3.28^{\mathrm{a}}$ & 0.11 \\
\hline 3 & $2.43^{\mathrm{b}}$ & 0.19 & $3.91^{\mathrm{a}}$ & 0.35 & $2.98^{\mathrm{sb}}$ & 0.16 \\
\hline$\geq 4$ & $2.00^{\mathrm{b}}$ & 0.17 & $4.07^{\mathrm{s}}$ & 0.31 & $2.74^{\mathrm{b}}$ & 0.15 \\
\hline
\end{tabular}

a,b Means within row having different superscript letters differ $(P<0.05)$.

${ }^{1} \mathrm{INT} 1$ = interval between enrollment and second examination; INT2 = interval between second and third examinations; INT3 = interval between enrollment and third examination.

flooring compared with cows maintained on concrete floors. However, when data were analyzed by lesion type, cows on concrete had a greater probability of having more heel erosions by the third examination compared with cows on rubber flooring. Although reports in the literature suggest that use of soft flooring materials such as rubber slats (Hultgren and Bergsten, 2001; Jungbluth et al., 2003) and straw yards (Somers et al., 2003) decrease the incidence and severity of claw lesions, our results agree with those of a previous study (Vokey et. al, 2001) evaluating an interlocking rubber flooring system that did not find an effect of the floor surface on the overall presence of claw lesions.

Previous studies reported an association between occurrence of heel erosions and digital dermatitis when housing environments were not hygienic (Bergsten and Pettersson, 1992; Philipot et al., 1994; Hultgren and

Table 2. Mean growth rates $(\mathrm{mm} / \mathrm{mo})$ for mature lactating dairy cows housed in free-stall barns under 2 different flooring conditions (rubber or concrete) during early lactation

\begin{tabular}{|c|c|c|c|c|c|c|}
\hline \multirow[b]{3}{*}{ Item } & \multicolumn{6}{|c|}{ Examination period $^{1}$} \\
\hline & \multicolumn{2}{|c|}{ INT1 } & \multicolumn{2}{|c|}{ INT2 } & \multicolumn{2}{|c|}{ INT3 } \\
\hline & Mean & $\mathrm{SE}$ & Mean & $\mathrm{SE}$ & Mean & $\mathrm{SE}$ \\
\hline \multicolumn{7}{|l|}{ Flooring } \\
\hline Rubber & $4.50^{\mathrm{a}}$ & 0.16 & $5.30^{\mathrm{a}}$ & 0.46 & $4.71^{\mathrm{a}}$ & 0.11 \\
\hline Concrete & $4.34^{\mathrm{a}}$ & 0.15 & $6.53^{\mathrm{b}}$ & 0.45 & $5.03^{\mathrm{b}}$ & 0.11 \\
\hline \multicolumn{7}{|l|}{ Lactation } \\
\hline 2 & $4.54^{\mathrm{a}}$ & 0.15 & $6.44^{\mathrm{a}}$ & 0.44 & $5.00^{\mathrm{a}}$ & 0.11 \\
\hline 3 & $4.20^{\mathrm{a}}$ & 0.23 & $5.96^{\mathrm{a}}$ & 0.63 & $4.86^{\mathrm{a}}$ & 0.15 \\
\hline$\geq 4$ & $4.53^{\mathrm{a}}$ & 0.19 & $5.35^{\mathrm{a}}$ & 0.56 & $4.74^{\mathrm{a}}$ & 0.14 \\
\hline
\end{tabular}

Bergsten, 2001). Increased foot problems may occur when cows' feet are excessively exposed to manure and urine, which increases the risk for the development of these 2 conditions. In our study, cows were maintained in free-stall barns that were designed and managed identically (i.e., floors were cleaned by a water flushing system 2 to 3 times daily and free stalls were bedded and groomed twice weekly). This management ensured that cows in our study were under the same manure and urine exposure. Our study indicates that floor surface also may have an independent effect on the occurrence of heel erosions.

Our finding of no difference in the number of claw lesions (except for heel erosions) between flooring types might have been affected by several factors. We focused on multiparous cows, of which only 15 to $18 \%$ had no claw lesions at the time of enrollment. Because of the elevated prevalence of preexisting claw lesions, our ability to detect differences in the development of subsequent claw lesions may have been compromised. Our study included only multiparous cows and we evaluated hoof health during the first 120 DIM. In studies in which the claw health of primiparous and multiparous cows has been evaluated, the recovery time from various claw lesions occurring around calving differed among lactation numbers, with first-lactation cows having a faster recovery from claw lesions than older cows (Greenough and Vermunt, 1991). In another study, the peak of lesion development after calving in first-lactation cows occurred at approximately 112 DIM, compared with 140 to 189 DIM peak for multiparous cows (Offer et al., 2000). It is possible that the follow-up evaluation period in our study (including only multiparous cows) was not long enough to allow significant changes in the development or recovery of claw lesions, or both.

Our approach to scoring claw health, which scored the lesion as present or absent rather than scoring its relative severity, would underestimate the effect of flooring if its main benefit was decreasing severity rather than preventing lesions. In a previous study, a system of evaluating severity was described (Greenough and Vermunt, 1991). A lesion such as sole hemorrhages was scored as: 0 ) no lesion, 1) slight discoloration, 2) moderate hemorrhages, 3) severe hemorrhages, and 4) exposed corium. We decided that evaluating the severity of a lesion under the study conditions would be difficult to replicate across all the evaluation periods and made no attempt to do more than to note the presence or absence of the lesion.

\section{Locomotion Scores}

For the group of cows scored as "not lame" during the first examination, the likelihood of becoming lame 
by the end of the study was greatest for cows on concrete floors compared with those on the rubber flooring. In addition, cows tended to be detected and treated more for lameness by the farm personnel when they were housed on concrete than on rubber flooring. Interestingly, regardless of the walking surface, the secondlactation cows diagnosed as "lame" during the first examination had a greater probability of improving their locomotion scores over time. In another study that evaluated the development of clinical lameness in cows housed on rubber flooring early in lactation, Vokey et al. (2001) found no difference in the cumulative incidence of clinical lameness among cows exposed to 3 different stall types (concrete, rubber mattresses, and sand) and 2 different flooring materials (concrete and rubber). Although these results differed from the ones in our study, their study may have confounded DIM with lactation number among some of their study groups.

\section{Claw Growth and Wear}

Greater rates of growth and wear observed for cows exposed to concrete in our study are in agreement with a previous report that showed both growth and wear affected by the abrasiveness of the flooring surfaces (Camera and Gravet, 1971). In a previous study, cows housed indoors on concrete had more claw growth and wear compared with cows housed outside on pasture environments (Hahn et al., 1986). Under normal physiological conditions, the claw is expected to grow and wear at similar rates (Vermunt and Greenough, 1995), with approximately 0.4 to $0.5 \mathrm{~cm}$ of claw growth per month (Prentice, 1973). In our study, we not only observed greater rates of growth than wear, but also greater values for both rates as lactation progressed. Our observations indicate that claw growth and wear are not uniform and can be affected not only by characteristics of the flooring surface, but also by DIM. This supports the findings of Hahn et al. (1986), who suggested that claw development is a dynamic process after parturition.

Further studies in which the claws of lactating dairy cows are measured for a longer period of time are necessary to better understand the growth and wear patterns of the claws through an entire lactation. In addition, it is of interest to determine whether the increased growth observed in our study for cows on concrete during INT2 would continue throughout lactation, and if so, how much this additional growth influences not only claw shape, but also overall hoof health.

\section{CONCLUSIONS}

Our study indicated that cows on concrete had a greater risk of developing heel erosions, were more likely to become lame during the study period, and had increased rates of claw growth and wear. These results indicate that a softer flooring surface such as interlocking rubber is beneficial for hoof health. However, future research should follow cows for a longer period during lactation to determine the long-term effect of different flooring surfaces on claw health.

\section{ACKNOWLEDGMENTS}

This study was funded by research grants from the Center for Food Animal Health (CFAH; University of California, Davis, School of Veterinary Medicine) and the American Association of Bovine Practitioners. Additional material support was provided by Animat. The authors gratefully acknowledge the cooperating dairy farm for their support of and assistance with this project.

\section{REFERENCES}

Bergsten, C. 2001. Effects of conformation and management system on hoof and leg diseases and lameness in dairy cows. Vet. Clin. North Am. Food Anim. Pract. 17:1-23.

Bergsten, C., and B. Pettersson. 1992. The cleanliness of cows in tied stalls and the health of their hooves as influenced by the use of electric trainers. Prev. Vet. Med. 13:229-238.

Camera, S., and H. O. Gravet. 1971. Investigations on hoof abrasions in cattle. Zuchtungskunde 43:111-125.

Clarkson, M. J., D. Y. Downham, W. B. Faull, J. W. Hughes, F. J. Manson, J. B. Merritt, R. D. Murray, W. B. Russell, J. E. Sutherst, and W. R. Ward. 1996. Incidence and prevalence of lameness in dairy cattle. Vet. Rec. 138:563-567.

Colam-Ainsworth, P., G. A. Lunn, R. C. Thomas, and R. G. Eddy. 1989. Behaviour of cows in cubicles and its possible relationship with laminitis in replacement dairy heifers. Vet. Rec. 125:573575.

Collick, D. W., W. R. Ward, and H. Dobson. 1989. Associations between types of lameness and fertility. Vet. Rec. 125:103-106.

Coulon, J. B., F. Lescourret, and A. Fonty. 1996. Effect of foot lesions on milk production by dairy cows. J. Dairy Sci. 79:44-49.

Faull, W. B., J. W. Hughes, M. J. Clarkson, D. Y. Downham, F. J. Manson, J. B. Merritt, R. D. Murray, W. B. Russell, J. E. Sutherst, and W. R. Ward. 1996. Epidemiology of lameness in dairy cattle: The influence of cubicles and indoor and outdoor walking surfaces. Vet. Rec. 139:130-136.

Ferguson, J. D., D. T. Galligan, and N. Thomsen. 1994. Principal descriptors of body condition score in Holstein cows. J. Dairy Sci. 77:2695-2703.

Greenough, P. R., and J. J. Vermunt. 1991. Evaluation of subclinical laminitis in a dairy herd and observations on associated nutritional and management factors. Vet. Rec. 128:11-17.

Hahn, M. V., B. T. McDaniel, and J. C. Wilk. 1986. Rates of hoof growth and wear in Holstein cattle. J. Dairy Sci. 69:2148-2156.

Hultgren, J., and C. Bergsten. 2001. Effects of a rubber-slatted flooring system on cleanliness and foot health in tied dairy cows. Prev. Vet. Med. 52:75-89.

Jungbluth, T., B. Benz, and H. Wandel. 2003. Soft walking areas in loose house systems for dairy cows. Pages 171-177 in Proc. Dairy Housing Conf., Forth Worth, TX. Am. Soc. Agric. Eng., St. Joseph, MI.

Lischer, C., P. Ossent, M. Raber, and H. Geyer. 2002. Suspensory structures and supporting tissues of the third phalanx of cows and their relevance to the development of typical sole ulcers (Rusterholz ulcers). Vet. Rec. 151:694-698. 
Livesey, C. T., and F. L. Fleming. 1984. Nutritional influences on laminitis, sole ulcer and bruised sole in Friesian cows. Vet. Rec. 114:510-512.

Lucey, S., G. J. Rowlands, and A. M. Russell. 1986. The association between lameness and fertility in dairy cows. Vet. Rec. 118:628-631.

Meinert, C. L., and Tonascia, S. 1986. Clinical Trials: Design, Conduct, and Analysis. Monographs in Epidemiology and Biostatistics. Vol. 8. Oxford University Press, New York, NY.

NRC (National Research Council). 2001. Nutrient Requirements of Dairy Cattle. 7th rev. ed. Natl. Acad. Sci., Washington, DC.

Offer, J. E., D. McNulty, and D. N. Logue. 2000. Observations of lameness, hoof conformation and development of lesions in dairy cattle over four lactations. Vet. Rec. 147:105-109.

Ossent, P., and C. Lischer. 1998. Bovine laminitis: The lesions and their pathogenesis. In Pract. 20:415-426.

Peterse, D. J., S. Korver, J. K. Oldenbroek, and F. P. Talmon. 1984. Relationship between levels of concentrate feeding and incidence of sole ulcers in dairy cattle. Vet. Rec. 115:629-630.

Philipot, J. M., P. Pluvinage, I. Cimarosti, P. Sulpice, and F. Bugnard. 1994. Risk factors of dairy cow lameness associated with housing conditions. Vet. Res. 25:244-248.

Prentice, D. E. 1973. Growth and wear rates of hoof-horn in Ayrshire cattle. Res. Vet. Sci. 14:285-290.

Shearer, J. K., D. Anderson, W. Ayars, E. Belknap, S. Berry, C. Guard, K. Hoblet, E. Hovingh, G. Kirksey, A. Langill, A. Mills, D. Miskimins, J. Osterstock, R. Price, D. Prigel, A. Roussel, S. R. van Amstel, R. Wallace, J. Wasson, N. Cook, E. F. Garret, D. E. Hostetler, and L. Schugel. 2004. A record-keeping system for capture of lameness and foot-care information in cattle. Pages
83-92 in The Bovine Practitioner. Vol. 38, No. 1. R. A. Smith, ed. American Association of Bovine Practitioners/Frontier Printers, Stillwater, OK.

Shearer, J. K., and S. R. van Amstel. 2001. Functional and corrective claw trimming. Vet. Clin. North Am. Food Anim. Pract. 17:53-72.

Somers, J. G., K. Frankena, E. N. Noordhuizen-Stassen, and J. H. Metz. 2003. Prevalence of claw disorders in Dutch dairy cows exposed to several floor systems. J. Dairy Sci. 86:2082-2093.

Sprecher, D. J., D. E. Hostetler, and J. B. Kaneene. 1997. A lameness scoring system that uses posture and gait to predict dairy cattle reproductive performance. Theriogenology 47:1179-1187.

Telezhenko, E., and C. Bergsten. 2005. Influence of floor type on the locomotion of dairy cows. Appl. Anim. Behav. Sci. 93:183-197.

Toussaint Raven, E., R. T. Halstra, and D. J. Peterse. 1985. Cattle Foot Care and Claw Trimming. Farming Press, Ipswich, UK.

Vermunt, J. J., and P. R. Greenough. 1995. Structural characteristics of the bovine claw: Horn growth and wear, horn hardness and claw conformation. Br. Vet. J. 151:157-180.

Vermunt, J. J., and P. R. Greenough. 1996. Sole hemorrhages in dairy heifers managed under different underfoot and environmental conditions. Br. Vet. J. 152:57-73.

Vokey, F. J., C. L. Guard, H. N. Erb, and D. M. Galton. 2001. Effects of alley and stall surfaces on indices of claw and leg health in dairy cattle housed in a free-stall barn. J. Dairy Sci. 84:2686-2699.

Warnick, L. D., D. Janssen, C. L. Guard, and Y. T. Grohn. 2001. The effect of lameness on milk production in dairy cows. J. Dairy Sci. 84:1988-1997.

Wells, S. J., A. M. Trent, W. E. Marsh, and R. A. Robinson. 1993. Prevalence and severity of lameness in lactating dairy cows in a sample of Minnesota and Wisconsin herds. J. Am. Vet. Med. Assoc. 202:78-82. 